\title{
Determination and distribution of various antinuclear antibodies in systemic lupus erythematosus patients by using immunoblot testing \\ Udayasri B $^{1, *}$, Swathi Prakasham ${ }^{1}$, Mujahabeen salma ${ }^{1}$ and Bhulakshmi ${ }^{1}$ \\ ${ }^{1}$ Department of laboratory Medicine, Block-C, Yashoda Hospitals, Somajiguda, Hyderabad, Telengana, India
}

\begin{abstract}
Background: Systemic lupus erythematosus (SLE) is defined as a multisystemic inflammation resulting from production autoantibodies against nuclear and cytoplasmic antigen.

Objective: The present study was undertaken to determine the distribution of various auto antibodies in SLE patients by line immuno assay.

Materials and methods: A prospective study conducted at Yashodha Hospital, Somajuguda, Hyderabad. A total number of 120 clinically diagnosed SLE patients serum samples were collected and they were subjected to indirect immunofluorescence testing (IIFT) to screen autoantibodies.
\end{abstract}

Results: Out of 120 patients 97 were males and 23 were females, predominant age group affected was 4160 years. Out of 120 patients 99 were positive by IIFT. Predominant pattern in IIFT is nucleus homogenous (54.54\%), followed by nucleus speckled (29.9\%). Out of 120 patients 69 were positive by ANA immunoblot, in that the predominant autoantibody was anti dsDNA antibody (40.57\%), followed by R0-52 (31.88\%), SSA (30.43\%). Out of 120 Samples 68 were positive by both IIFT and immunoblot, 31 were only positive by IIFT, 20 were negative by both and one was only positive by immunoblot.

Conclusion: The study stresses on using IIFT as screening test for SLE. It should be followed by ANA immunoblot to determine specific antibody, which inturn helps in diagnosis, evaluation and follow-up of SLE patient.

Keywords: systemic lupus erythematosus; autoantibodies; antinuclear antibodies; indirect immuno fluorescence testing; immunoblot testing

\begin{abstract}
*Corresponding author: Dr. Udayasri B, Consultant Microbiologist, Department of Laboratory Medicine, Yashoda hospitals, Somajiguda, India. Mobile: 9247576467; Email: udayasree09@gmail.com
\end{abstract}

Received 18 April 2018; Revised 07 June 2018; Accepted 15 June 2018; Published 22 June 2018

Citation: Udayasri B, Prakasham S, Salma M, Bhulakshmi. Determination and distribution of various antinuclear antibodies in systemic lupus erythematosus patients by using immunoblot testing. J Med Sci Res. 2018; 6(3):68-73. DOI: http://dx.doi. org/10.17727/JMSR.2018/6-12

Copyright: (C) 2018 Udayasri B et al. Published by KIMS Foundation and Research Center. This is an open-access article distributed under the terms of the Creative Commons Attribution License, which permits unrestricted use, distribution, and reproduction in any medium, provided the original author and source are credited. 


\section{Introduction}

Lupus is defined as a multisystemic inflammation resulting from abnormal immunological response. There are four types of lupus, they are as follows neonatal lupus erythematosus (NLE), discoid lupus erythematosus (DLE), drug- induced lupus (DIL), and systemic lupus erythematosus (SLE) [1]. Out of four types systemic lupus erythematosus is most common type [2]. Systemic lupus erythematosus is characterized by multisystemic chronicinflammatory disease associated with periods of exacerbations and remission [3]

SLE is diagnosed in approximately 20-150 persons $/ 1,00,000$ population [4]. It typically affects middle-aged females, but can affect males or females at any age group [5]. Organs most commonly involved in SLE include joints, skin, mucus membranes, bone marrow and kidney [6]. Ongoing disease process cumulatively damages the affected system over a period of time leading to significant interference with quality of life [7]. Early detection and prompt treatment is necessary in SLE patients.

The main pathophysiology behind SLE is presence of auto reactive $\mathrm{B}$ and $\mathrm{T}$ lymphocytes. They are responsible for production of broad and heterogeneous group of autoantibodies [8]. Indeed around 116 autoantibodies were reported in SLE patients. Either they are against nuclear or cytoplasmic antigens. Anti nuclear antibodies are common and reported in $90 \%$ of SLE patients [8].

The commonest antigens for which auto anti bodies produced in SLE are double-stranded DNA (dsDNA), nucleosomes, histones, n/ RNP, Sm, SSA, SSB, PCNA, $\mathrm{KU}$, Rib Protein, RO-52, Cardiolipin, Beta 2 globulin [9].

These autoantibodies play a key role in severe organ damage in SLE by immune complex mediated damage [10]. Beyond elucidating the mechanism behind the disease and understanding the pathogenic role, detection of specific autoantibodies against a particular antigen in SLE might also help in 1) Confirmation of diagnosis, 2) Help to predict disease association like antibody against dsDNA is associated with increased disease activity, increased chances of vasculitis and nephritis; autoantibodies to SSA antigen in mother predict chances of neonatal lupus with congenital heart block; autoantibody against $\beta 2$ glycoprotein and cardiolipin predicts increased chances of intravascular coagulation, fetal loss and thrombocytopenia; auto antibodies to Rib protein is associated with psychosis and CNS lupus [8], 3) Determination of autoantibodies also has therapeutic implication [11], 4) Determination of specific autoantibodies not only help in diagnosis, but also have prognostic value according to American association of Rheumatology criteria [8]. Considering all the above determination of specific autoantibodies in SLE patients is very important.

The present study was undertaken to determine the distribution of various auto-antibodies in SLE patients by line immuno assay, which in turn helps in confirmation of diagnosis and identification of related consequences in SLE patients which guide the physician in proper evaluation and treatment.

\section{Materials and methods}

The present study is a prospective observational study conducted at a tertiary care hospital, over a period of six months from May 2016 to October 2017. A total number of 120 patients were included in the study.

Patientinclusion criteria: Clinically diagnosed cases of SLE according to American college of rheumatology criteria were included under the study. According to ACR a patient having any of the four or more findings of the following will be diagnosed as SLE. The criteria includes photosensitivity, malar rash, discoid rash, oral ulcers, arthritis, serositis, renal disorders, neuronal disorders, hematological manifestations, presence of ANA indirect immuno fluorescence test positivity [8].

Patient exclusion criteria: patients with other autoimmune diseases were excluded from the study (mixed connective tissue diseases; rheumatoid arthritis, Sjogren's syndrome etc.

\section{Processing}

Serum samples were collected from the patients according to standard guidelines. The samples were subjected to ANA screening by indirect immuno fluorescence testing. Then ANA immunoblot testing was done to determine specific autoantibody. 


\section{Indirect immune fluorescence testing}

Indirect immune fluorescence testing is the gold standard test for detection of autoantibodies against nuclear and cytoplasmic antigens [12]. In the present study the test is based on BIOCHIP technology where the chips are coated with Hep-2010 cells and primate liver cell lines and these biochips were placed on a polystyrene microscopic slide (EUROIMMUNEGermany, Medizinische labor diagnostic AG). The cell line act as substrate and any autoantibody to either nuclear or cytoplasmic antigen will bind with the component of cell, which will be detected with the help of fluorescine labeled anti human globulin.

Patient samples were diluted with sample diluent (1:100) prior to performing the test. The test was done according to manufacturers guidelines. The BIOCHIP slide was examined under fluorescent microscope with excitation filter $450-490 \mathrm{~nm}$, under 20X and 40X objectives. The patterns were observed and recorded. Quality control was done with every test run by using Standard positive and negative control sera provided in the kit.

\section{ANA immune-blot testing}

Euroline test is a qualitative in vitro assay based on principle line immunoassay. It is used for detection of autoantibodies against 14 different antigens in patient serum. The antigens coated on the strip are n/RNP, Sm, SSA, SSB, Histones, dsDNA, Nucleosomes, PCNA, RO-52, RiB - protein, Scl -70, PM Scl-100, Jo-1, CENPB, AMA-M2.

These strips were incubated with diluted (1:100) patient serum samples in a tray containing troughs for $30 \mathrm{~min}$ on a rotary shaker. After washing the strip for three times, then enzyme conjugate was added and incubated for 30 minutes on a rotary shaker at room temperature. After washing substrate solution was added into the trough and incubated for 10 min. Then the strip was washed and allowed to dry. The results were read with scanner using Euroblot Master software.

\section{Results}

A total number of 120 patients were included in the present study. Out of them 97 (80.83\%) were females and $23(19.16 \%)$ were males showing predominance of disease in females. In the present study, out of 120 patients maximum age group effected was 41-60 years i.e., $40 \%(n=48)$, followed by $21-40$ years i.e $38.33 \%(\mathrm{n}=46)$ (Table 1).

Table 1: Age distribution.

\begin{tabular}{|lcc|}
\hline Age group & Number & Percentage $\%$ \\
\hline$<20$ & 9 & $7.5 \%$ \\
$21-40$ & 46 & $38.33 \%$ \\
$41-60$ & 48 & $40 \%$ \\
$61-80$ & 16 & $13.33 \%$ \\
$>80$ & 1 & $0.83 \%$ \\
Total & 120 & $100 \%$ \\
\hline
\end{tabular}

Indirect immuno fluorescence test was positive in 99 patients comprising up to $82.5 \%$ and negative in 21 patients comprising up to $17.5 \%$. In indirect immuno fluorescence test commonest pattern observed was nucleus homogeneous pattern comprising up to $54.54 \%(\mathrm{n}=54)$, followed by nucleus speckled pattern comprising up to $29.9 \%(n=29)$.

Distribution of other patterns were nucleus nucleolar pattern is seen in $7.07 \%(\mathrm{n}=7)$, mitosis pattern was seen in $4.04 \%(n=4)$, cytoplasm granular pattern was observe in $3.03 \%(n=3)$ and mixed pattern i.e., nucleus homogeneous and nucleus granularity was observed in 2.02\% $(\mathrm{n}=2)$ cases (Figure 1).

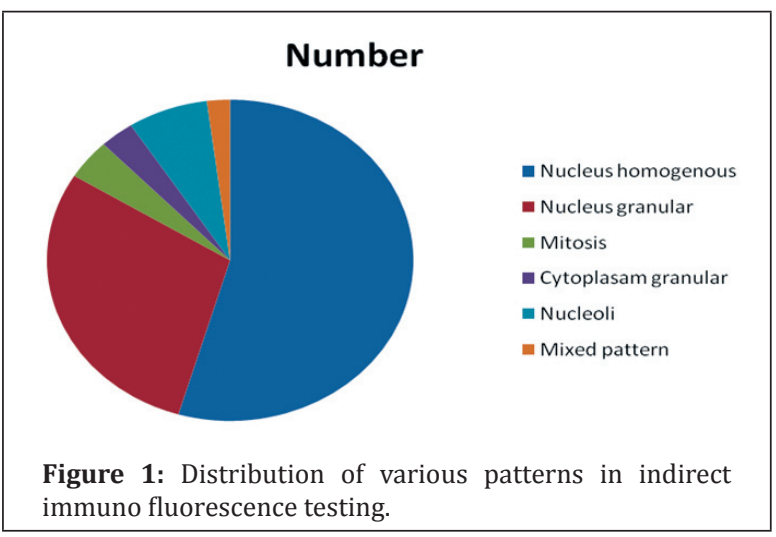

Out of 120 cases a total number of 69 were positive and 51 were negative by ANA profile testing. Out of 69 patients only single autoantibody against a specific antigen was present in 34 cases comprising $49.27 \%$. Multiple autoantibodies were present in 35 patients comprising up to $50.72 \%$.

Maximum number of patients showing autoantibodies against dsDNA comprising up to 
40.57\% ( $\mathrm{n}=28)$, followed by R0-52 31.88\% $(\mathrm{n}=22)$, SSA $30.43 \%(n=21)$.

The other autoantibodies, distributed as autoantibodies to n/RNP were seen in $26.08 \%$, autoantibodies to histones in $17.39 \%$, autoantibodies to $\mathrm{Sm}$ in $11.59 \%$, autoantibodies to SSB in $7.42 \%$, autoantibodies to PCNA in 7.42\%, autoantibodies to RiB Protein were seen in $7.42 \%$. Autoantibodies to $\mathrm{KU}$ were not reported in the present study (Figures 2 and 3 )

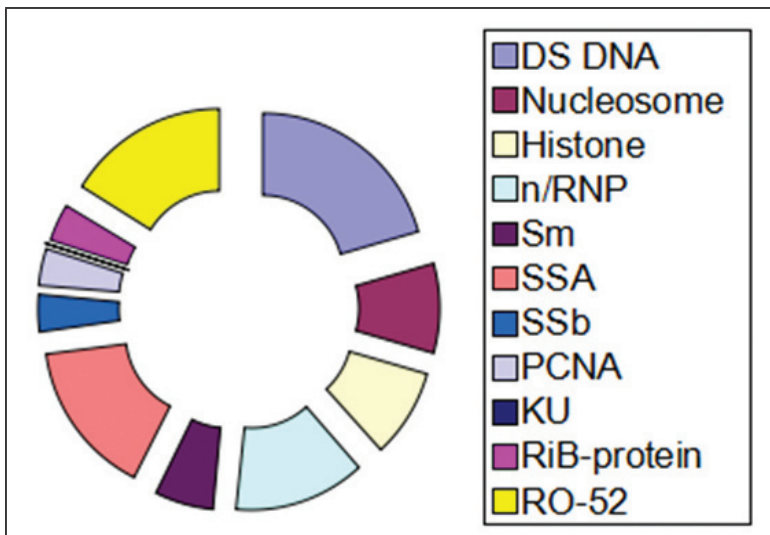

Figure 2: Distribution of various auto-antibodies in immunoblot testing.

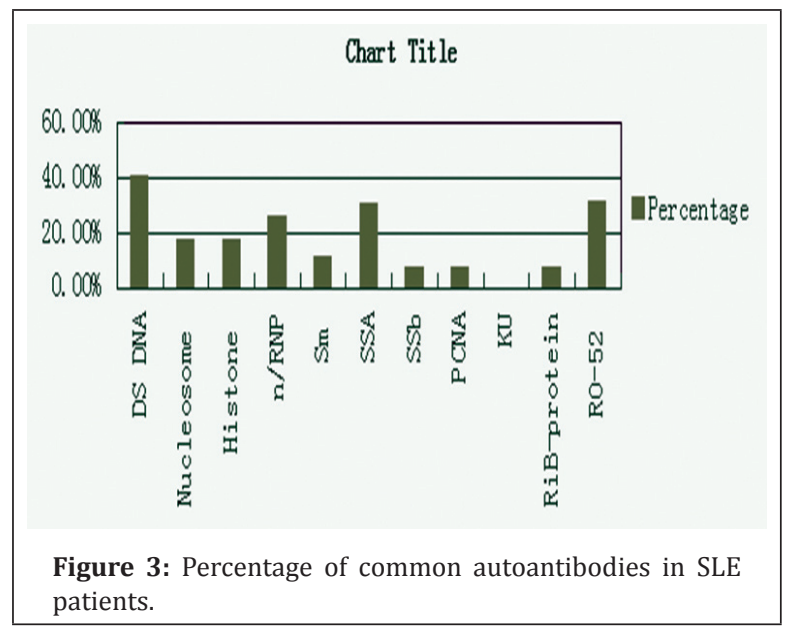

Out of 120 A total number of $68(\mathrm{a}=68)$ samples were positive by both IIFT and ANA profile testing, 31 samples were positive by IIFT but negative by ANA profile testing ( $b=31), 20$ samples were negative by both profile and IIFT $(\mathrm{d}=20)$. Only one patient was positive by profile but negative by IIFT ( $\mathrm{c}=1$ ). The Chi squire test shows a $P$ value of $<0.00001$ (significant at $<0.5$ ). The above calculations interpret the results as significant (Table 2).
Table 2: Chi square test statistics.

\begin{tabular}{|c|c|c|c|}
\hline & $\begin{array}{c}\text { ANA profile } \\
(+)\end{array}$ & $\begin{array}{c}\text { ANA profile } \\
(-)\end{array}$ & \\
\hline IIFT positive & $\begin{array}{c}a=68 \\
(56.92) \\
(2.15)\end{array}$ & $\begin{array}{c}b=31 \\
(42.08) \\
(2.92)\end{array}$ & $a+b=100$ \\
\hline \multirow[t]{2}{*}{ IIFT negative } & $\begin{array}{c}c=1 \\
(12.08) \\
(10.16)\end{array}$ & $\begin{array}{c}\mathrm{d}=20 \\
(8.93) \\
(13.74)\end{array}$ & $c+d=20$ \\
\hline & $a+c=69$ & $b+d=51$ & $\mathrm{a}+\mathrm{b}+\mathrm{c}+\mathrm{d}=120$ \\
\hline
\end{tabular}

Chisquare test statistics $=28.97 ; \mathrm{P}$-value $<0.00001$ (Significant $<0.5)$.

\section{Discussion}

In the present study the disease predominance is seen in females. It has been reported in many studies like Yacoub Wasef SZ et al. and Weckerle et al. $[13,14]$. In the present study the most common age group effected is $41-60 y e a r s$ i.e. $40 \%(n=48)$, Followed by $21-40$ years i.e., $38.33 \%(n=46)$, which is correlating with the report odManole COJOCARU [15].

IIFT was reported negative in 21 clinically suspected cases of SLE in the present study. Similar results were reported by McHardy et al. [16]. The commonest Immunoflourescence pattern reported in present study is Nucleus homogenous pattern comprising upto $54.04 \%$, which is correlating with Frodlund et al., and Sjöwall et al $[6,17]$.

In the present study IIFT showed nucleus granularity in 29.29\%, Nucleus nucleolar pattern in $7.07 \%$, Mixed both homogenous and granular pattern in $2.02 \%$, which is correlating with Frodlund et al. [6].

In the presentstudy the most common autoantibodies in SLE patients was anti Double standard DNA comprising up to $40.57 \%$, anti-nucleosome antibodies seen in $7.42 \%$, anti-histone antibodies seen in $17.39 \%$, comparatively higher prevalence has been reported in literature up 70\%, 60\%, 60\% respectively. This may be due to geographical, environmental and genetic variation among the population [18-21].

In the present study anti R0-52, SSA antibodies were reported up to $31.88 \%, 30.43 \%$ respectively, which is correlating with Marks et al., Wang et al., and Chan et al., $[18,22,23]$.

In the present study antibodies to N/RNP, SSB were reported in $26.08 \%, 7.42 \%$. the same results were 
reported by Wang et al., and Williamson et al., who reported antibodies to $\mathrm{n} / \mathrm{RNP}$ up to $21 \%, 30 \%, 32 \%$ respectively and antibodies to SSB were reported in $8 \%, 10 \%, 13 \%$ patients respectively, D15, D16 [22, $24,25]$.

Present study autoantibodies to sm were found in $11.59 \%$ cases which are correlating with Wang CL who reported 15\%, D12.

In the present study autoantibodies to RiB Protein was reported in $7.42 \%$, which is comparatively low with Wang et al (15\%). In the present study autoantibodies to PCNA were reported in $7.42 \%$, which is correlating with Wang et al (8\%). Anti bodies to Cardiolipin, Beta 2 globulin was not tested in the present study as the antigens were not included in the profile.

In the present study out of 120 patients who were clinically diagnosed as SLE, 99 were positive by IIFT, but out of these patients 31 were negative by profile testing though they are suffering from the disease. This may be due to restricted number of antigens in the profile or immunoblot testing, But IIFT which is a gold standard test, having around 200 antigens as substrate in the form of whole nucleated cell, which explains the higher sensitivity of IIFT.

In the present study the $\mathrm{P}$ value is 0.00001 which is much less than 0.5 showing the result in the study as significant. Which means IIFT should be used as screening test. But always a Positive IIFT should be followed by ANA immunoblot test to determine the specific antibody which helps in various aspects like confirmation of diagnosis, prediction of complications, guiding the treatment.

In the present study autoantibodies to dsDNA are common in SLE Patients which is a known fact. But prevalence of auto antibody to nucleosome and histones are less frequently seen in the study population compared to literature. The prevalence of RO-52 and SSA is high in SLE patients at our region.

\section{Conclusion}

The present study supports indirect immuno fluorescence test as gold standard test and should be used as screening test. But all the IIFT positive patients should be subjected to ANA immunoblot to determine the specific auto antibody, which inturn helps in confirmation of diagnosis, evaluation of patients for future complications and helps guiding treatment.

\section{Conflicts of interest}

Authors declare no conflicts of interest.

\section{References}

[1] Maidhof W, Hilas O. Lupus: An Overview of the disease and management options. P T. 2012; 37(4):240-249.

[2] Lawrence RC, Helmick CG, Arnett FC, Deyo RA, Felson DT, et al. Estimate of the prevaklence of arthritis and selected musculoskeletal disorders in the United states. Arthritis rheum. 1998; 41(5):778-799.

[3] Ahmed N, Shigidi M, Agib AN, Abdelrahman H, Taha E. Clinical features and antinuclear antibodies profile among adults with systemic lupus erythematosus and nephritis: A cross- sectional study. Pan Afr Med J. 2017; 27:114.

[4] Chakravarthy EF, Bush TM, Manzi S, Clarke AE, Ward MM. Prevalence of adult systemic lupus erythemutosus in California and Pennsylvania in 2000: Estimate obtained using hospitalization data. Arthritis Rheum. 2007; 56(6):20922094.

[5] Pons-Estel GJ, Alarcon GS, Scofield L, Reinlib L, Cooper GS. Understanding the epidemiology and progressing of systemic lupus erythemutosus. Semin Arthritis Rheum. 2010; 39(4):257-268.

[6] Frodlund M, Dahlström O, Kastbom A, Skogh T, Sjowall C. Association between anti nuclear antibody staining patterns and clinical features of systemic lupus erythemutosus: Analysis of a regional Swedish register. BMJ open. 2013; 3(10):e003608.

[7] Lateef A, Petri M. Unmet medical needs in systemic lupus erythemutosus. Arthritis Res Ther. 2012; 14 Suppl 4:S(4).

[8] Cozzani E, Drosera M, Gasparini G, Parodi A. Serology of lupus erythematosus: Correlation between immunopathological features and clinical aspects. Autoimmune Dis. 2014; 2014:321359.

[9] Tomer Y, Buskila d, Shoenfeild Y. Pathogenic significance and diagnostic value of lupus autoantibodies. Int Arch Allergy Immunol. 1993; 100(4):293-306.

[10] Rekvig OP, Putterman C, Casu C, Gao HX, Ghirardello A, et al. Autoantibodies in lupus: Culprits or passive bystander? Autoimmun Rev. 2012; 11(8):596-560.

[11] Solomon DH, Kavanaugh AJ, Schur PH, American College of Rheumatology Ad Hoc Committee on Immunologic Testing Guidelines. Evidence-based guidelines for the use of immunologic tests: Antinuclear antibody testing. Arthritis Rheum. 2002; 47(4):434-444.

[12] Meroni PL, Schur PH. ANA screening: An old test with new recommendations. Ann Rheum Dis. 2010; 69(8):14201422.

[13] Yacoub Wasef SZ. Gender differences in systemic lupus erythematosus. Gend Med. 2004; 1(1):12-17.

[14] Weckerle CE, Niewold TB. The unexplained female predominance of systemic lupus erythematosus: Clues from genetic and cytokine studies. Clin Rev Allergy Immunol. 2011; 40(1):42-49.

[15] Cojocaru M, Cojocaru IM, Silosi I, Vrabie CD. Manifestations of systemic lupus erythematosus. Maedica (Buchar). 2011; 6(4):330-336. 
[16] McHardy KC, Horne CH, Rennie J. Antinuclear antibodynegative systemic lupus erythematosus-how common? J Clin Pathol. 1982; 35(10):1118-1121.

[17] Sjöwall C, Sturm M, Dahle C, Bengtsson AA, Jönsen A, et al. Abnormal antinuclear antibody titers are less common than generally assumed in established cases of systemic lupus erythematosus. J Rheumatol. 2008; 35(10):1994-2000.

[18] Marks SD, Tullus K. Autoantibodies in systemic lupus erythematosus. Pediatr Nephrol. 2012; 27(10):1855-1868.

[19] Arinuma Y, Yanagida T, Hirohata S. Association of cerebrospinal fluid anti-NR2 glutamate receptor antibodies with diffuse neuropsychiatric systemic lupus erythematosus. Arthritis Rheum. 2008; 58(4):1130-1135.

[20] Hansen KE, Arnason J, Bridges AJ. Autoantibodies and common viral illnesses. Semin Arthritis Rheum. 1998; 27(5):263-271.

[21] Isenberg DA, Manson JJ, Ehrenstein MR, Rahman A. Fifty years of anti-ds DNA antibodies: Are we approaching journey's end? Rheumatology (Oxford). 2007; 46(7):10521056.

[22] Wang CL, Ooi L, Wang F. Prevalence and clinical significance of antibodies to ribonucleoproteins in systemic lupus erythematosus in Malaysia. $\mathrm{Br} \mathrm{J}$ Rheumatol. 1996; 35(2):129-132.

[23] Chan EK, Hamel JC, Buyon JP, Tan EM. Molecular definition and sequence motifs of the $52-\mathrm{kD}$ component of human SS-A/Ro autoantigen. J Clin Invest. 1991; 87(1):68-76.

[24] Williamson GG, PennebakerJ,BoyleJA.Clinical characteristics of patients with rheumatic disorders who possess antibodies against ribonucleoprotein particles. Arthritis Rheum. 1983; 26(4):509-515.

[25] Williamson GC, Mary A, Snyder LM, Wallach JB. Autoimmune and miscellaneous diseases in Wallach's interpretation of diagnostic tests, p. 1035,Wolters Kluwer, Lippincott Williams \&Wilkins, Philadelphia, Pa, USA. 2011. 